

\title{
ESTIMATION OF RESIDENTIAL WATER DEMAND WITH IMPRECISE PRICE PERCEPTION
}

\section{Marie-Estelle BINET ${ }^{a}$ Fabrizio CARLEVARO ${ }^{b}$ Michel PAUL $^{c}$}

${ }^{\text {a }}$ Corresponding author: CREM (UMR 6211 CNRS), University of Rennes 1, marieestelle.binet@univ-rennes1.fr

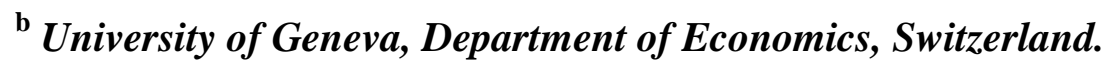

${ }^{c}$ CEMOI, University of Réunion, France.

\begin{abstract}
Based on a detailed sample of time unbalanced panel data on residential water consumption in the French overseas territory of Réunion, we investigate which water price specification should be included in an econometric analysis of residential water demand. To identify the relevant price variable, we estimate the residential demand function for water using the perceived price methodology developed by Shin (1985). The empirical results support the hypothesis that households respond to the average price perceived from the latest water bill. Households facing an increasing block rate schedule perceive a price of water that is generally lower than its actual marginal price. This conclusion emphasizes the relevance of a marginal price information policy to promote water saving.
\end{abstract}

JEL code: D12, C26, Q25.

Key-Words: billing information, price perception, residential demand for water, time unbalanced panel data. 


\section{Introduction}

As shown by the number of surveys recently published in the literature, the estimation of residential demand for water is a major issue in environmental economics (see Arbuès et al. (2003), Dalhuisen et al. (2003), Worthington and Hoffman (2008), Nauges and Whittington (2010)). A large part of this empirical literature aims to obtain consistent estimates of the price elasticity of demand for water as a prerequisite to analyze the relevance of pricing policies for a demand-side management of water consumption.

As water tariff schedules are often complex, with increasing or decreasing block rates and fixed charges, an important issue discussed in the literature is the provision of a relevant specification of the price variable for residential water consumption analysis. The discussion generally focuses on whether to use the average price of water or the marginal price measured as the block rate charged on the last unit consumed. A perfectly informed consumer should react to the marginal price, but there is a strong presumption that imperfect information may confuse consumer perception of block rates. Therefore, in the case of incomplete information, the consumer may respond to other price indicators, in particular the average price which can be obtained easily by dividing the water bill by water consumption.

To date, the determination of the price variable to which consumers respond has been tackled as an empirical issue. Howe and Linaweaver (1967) were the first to discuss and compare average and marginal prices for water demand analysis. In a first approximation, the price providing the best fit is presumed to be the price perceived by consumers (see Foster and Beattie (1981)). Ruijs et al. (2008) provide a more recent study comparing the use of average versus marginal prices in water demand modelling. 
At least two formal statistical tests of average versus marginal prices have been developed in the literature to gain a better insight into the issue of consumer price perception. The first was suggested by Opaluch (1982). Unfortunately, this test can lead to the rejection of both water price assumptions by preventing one from discriminating between these two price specification, as occured in the study of Ruijs et al. (2008). For this reason, we did not use Opaluch's test in our study.

The second test was suggested by Shin (1985) to analyze residential electricity demand of households faced with a declining block rate schedule. The test is based on a specification of the electricity price perception, which is a weighted geometric average of marginal and average prices, where the weight plays the role of a price perception parameter leading to one of these two prices depending on whether its value is 0 or 1 . Thus, the relevant price perception specification can be identified by estimating and testing the value of the price perception parameter. Nieswiadomy and Molina (1991) first used this methodology to identify, through a time series approach, the price perception of residential water consumers faced with a multistep block rate schedule. To the best of our knowledge, with the exception of the working paper by Kavezeri-Karuaihe et al. (2005), no recent studies have used Shin's methodology.

This paper intends to contribute to the literature on empirical residential water demand by applying Shin's methodology to a unique micro data set collected on an island where the use of water resources has become a source of increasing controversy. We use a sample of 449 useful water bills (between 1 and 3 water bills per household) collected from a household survey in the French overseas territory of Réunion. We have time unbalanced panel data as residential water consumption is observed for durations and periods of time that change across the surveyed households. 
The conclusions that we draw from this empirical study also have innovative implications for policy analysis. In the case of imperfect information and increasing block rates, consumers may be led to think that each additional unit of water consumed is paid at an average price which turns out to be smaller than the actual price paid, namely the marginal price. Therefore, an effective water saving policy can consist in improving consumer's price information, i.e. by providing households information about the marginal price they pay on their water bill. Using our econometric results, we assess by simulation the magnitude of the impact of such an information pricing policy on water conservation. Our simulation shows that if households set their water demand according to marginal price instead of perceived price, then average water consumption would decline substantially.

This paper proceeds as follows. In section 2, the model specification is presented. Section 3 describes the data used in our empirical application. Section 4 examines and discusses the empirical results. Section 5 concludes by outlining recommendations intended to improve the information provided to households on the cost of water, thereby allowing them to rationally respond to pricing policies aiming to promote household water saving behaviour.

\section{Modelling residential water demand}

In this section, a description of the pricing model is followed by a presentation of the water demand specification.

\subsection{Pricing model}

On Réunion island, as in numerous other locations, the pricing of residential water consists of 
several increasing consumption blocks (between 1 and 4 depending on the municipality considered).

To simplify the presentation, consider a block rate schedule consisting of two consumption blocks with increasing prices $\pi_{1}$ and $\pi_{2}$ and a fixed charge $F$. The consumer's budget constraint can be written as follows:

(1) $F+\pi_{1} q+p_{x} X=Y$,

if the consumer's actual water consumption, denoted by $q$, is located in consumption block 1 and as:

(2) $F+\pi_{1} b_{1}+\pi_{2}\left(q-b_{1}\right)+p_{x} X=Y$,

if $q$ is located in consumption block 2 , with $b_{1}$ the highest consumption level in block 1. $p_{x}$ and $X$ are respectively a price index and the corresponding consumption of other private goods, while $Y$ is the household income.

According to Nordin (1976), in both cases the budget constraint can be rewritten as a standard budget constraint of the form:

(3) $\pi q+p_{x} X=Y-F+D$

with

(4) $D=\left\{\begin{array}{c}0, \text { if } 0 \leq q \leq b_{1} \\ \left(\pi_{2}-\pi_{1}\right) b_{1}, \text { if } q>b_{1}\end{array}\right.$

and $\pi$ is the "marginal price" of water, namely: either $\pi_{1}$ if $0 \leq q \leq b_{1}$ or $\pi_{2}$ if $q>b_{1}$. This formalization can be easily generalized to the case of a multi block rate schedule.

Formula (3) claims that a perfectly informed water consumer should react not only to 
marginal price, but also to changes in intra-marginal prices through an income increase measured by Nordin's difference variable $D$, expressing the refunding to which the consumer is entitled whether he had paid his entire water consumption at the marginal price.

But, if consumers are not perfectly informed about the method used by the residential water provider to price water consumption, their price perception may lie between marginal and average price $\bar{\pi}$, so defined:

(5) $\bar{\pi}=\pi-\frac{D-F}{q}$

which is lower than marginal price $\pi$ when there is no fixed charges or when Nordin's $D>F$.

According to Shin (1985), the perceived price to which an imperfectly informed consumer responds may be expressed by the following formula:

(6) $p=\pi\left(\frac{\bar{\pi}}{\pi}\right)^{k}$.

According to this formula the consumer responds to marginal price $\pi$ when the perception parameter $k$ is equal to zero and to average price $\bar{\pi}$ when $k$ is equal to one. Assuming $\bar{\pi}<\pi$ , under an increasing block rate schedule, the perceived price lies between average and marginal price if $0<k<1$, whereas $p<\bar{\pi}<\pi$ when $k>1$ and $p>\pi>\bar{\pi}$ when $k<0$.

Parameter $k$ was estimated for the first time by Shin (1985) for electricity demand, then by Nieswiadomy and Molina (1991), Nieswiadomy (1992) and Nieswiadomy and Cobb (1993) for water demand. These studies had mixed results. Under a declining rate schedule, Shin (1985) found a price perception parameter equal to 1.007 , with the null hypothesis $k=1$ not rejected. He concluded that electricity consumers respond to the average price. Nieswiadomy 
(1992) and Nieswiadomy and Cobb (1993) reported similar results. Nieswiadomy and Molina (1991) obtained a non significant parameter estimate under an increasing water consumption block rate schedule and concluded that the consumers respond to marginal prices. However, for a decreasing block rate schedule, they found a price perception parameter estimate not significantly different from that in Shin (1985).

\subsection{Residential water demand specification}

The residential water demand function proposed by Shin (1985) assumes a constant elasticity with respect to household income and perceived price. He used a partial adjustment model with time series data. We estimate a static form of Shin's specification as we use time unbalanced panel data. So, consumption data were converted to a daily consumption per household. It is written as a regression equation of the form:

(7) $\ln q=\alpha_{0}+\alpha_{1} \ln Y+\alpha_{2} \ln p+x \beta+\varepsilon$

where $\alpha_{1}$ and $\alpha_{2}$ denote income and perceived price elasticities, $x$ a vector of additional explanatory variables and $\varepsilon$ a random disturbance.

Replacing in this equation the unobservable perceived price $p$ by functional form (6) leads to the derived regression equation:

(8) $\ln q=\alpha_{0}+\alpha_{1} \ln Y+\alpha_{2} \ln \pi+\alpha_{2} k \ln \left(\frac{\bar{\pi}}{\pi}\right)+x \beta+\varepsilon$

which is linear with respect to parameters $\alpha_{0}, \alpha_{1}$ and $\beta$, but nonlinear with respect to the perceived price elastricity $\alpha_{2}$ and the perception parameter $k$. 
In addition to price and income, one important explanatory variable is household size $(N)$ including the number of children and the number of adults in the family. If we consider the entire family's daily needs, we expect that water consumption will increase with household size. However, we expect a greater impact of the percentage of non-working adults (PNWA), as they spend more time at home than other family members.

Generally, outdoor water use is a major determinant of residential water consumption. The presence of a garden is an important factor on Réunion island as in $2004,77 \%$ of households lived in a house with a garden, compared with $30 \%$ in mainland France. The presence of a garden is defined here as a dichotomous variable that takes the value of one if the family has a garden, zero otherwise. We would have liked to use data giving the size of the garden, but our data set only noted the presence or absence of a garden without specifying garden size.

Outdoor uses are supposed to be influenced by weather conditions. We therefore decide to analyze the impact of the presence of a garden conditional to climate effects on water consumption (WEATHER). To this purpose, an interaction variable (GARD.WEATHER) defined by multiplying the dichotomous garden variable by the WEATHER variable has also been introduced into regression equation (8), leading to the residential water demand specification:

(9) $\ln q=\alpha_{0}+\alpha_{1} \ln Y+\alpha_{2} \ln \pi+\alpha_{2} k \ln \left(\frac{\bar{\pi}}{\pi}\right)+\alpha_{3} \ln N+\alpha_{4} P N W A+\alpha_{5}$ GARD.WEATHER $+\varepsilon$.

WEATHER is measured by the percentage of non rainy days over the billing period. 


\section{Household survey on Réunion island}

The analysis is based on a unique survey dataset covering the entire territory of Réunion island. We first offer a description of the survey and then introduce the data selected for empirical analysis.

\subsection{Household survey}

Réunion, a French overseas territory lying in the Indian Ocean, is $70 \mathrm{~km}$ long and $50 \mathrm{~km}$ wide, with the population in 2004 estimated to be approximately 700,000 inhabitants. In 2004, a great part of the population was quite young ( $40 \%$ are under 40 years old). Furthermore, the population growth rate and the unemployment rate (about 30\%) are both high. The climate is rather humid and tropical. The rainy season (from December to April) follows the dry season (from May to November). Rainfall differs considerably according to the geographical location: the northeast of the island receives about $70 \%$ of the total rainfall. Urban development mainly occurs in the northwest of the island, where the weather is dry. Lastly, household use of water in 2004 appears quite high, as the daily water consumption level on Réunion, computed with aggregate data, is 269 litres per inhabitant compared to an average of 150 litres on mainland France, Coutelier and Le Jeannic (2007).

Water therefore has become the source of increasing controversy on Réunion because supply is failing to meet demand in many areas, especially in the western part of the island. In this context, the Regional Directorate for the Environment (DIREN) was given the important job 
of setting up an overall water management system based on a law passed in 1992 intended to secure the future provision of water on Réunion. The long term objective of the water management plan is to reduce water consumption by $30 \%$ over 20 years (or about $1.32 \%$ per year).

This paper analyzes the data of a survey sample performed by the authors on Réunion on behalf of the Regional Directorate for the Environment. The objective of the survey was to identify the reasons for the comparative over-consumption of water by island inhabitants compared to those on mainland France. The stratified random survey was financed by DIREN and conducted in 2004 on a sample of households living on Réunion. The survey was designed as a proportionate stratified random survey according to municipalities, on a sample of 2,000 households representing $1 \%$ of the total household population of Réunion. Carlevaro et al. (2007) provide further description of the survey.

The questionnaire included 25 questions concerning:

- Household socio-economic characteristics (sex, family head age and occupation, family income and size, number of working adults and children, and if they are property owners or tenants).

- Housing characteristics (detached house or flat, age, number of rooms, altitude).

- Water consumption equipment (swimming pool, washing machine, dishwasher, garden ownership).

- Consumption habits (washing frequency, business activity at home to verify that only domestic users are targeted).

Carried out by telephone, this first step survey was followed by a mailing to 1000 volunteer households intended to collect information on the volume of water consumption displayed on the last three bills that they had received (covering one year). Unfortunately, this second step survey provided 173 reliable responses supplying us with 449 useful water bills. Since the 
billing period varies across municipalities, consumption data were converted to a daily consumption per household (in litres). Corresponding daily weather indicators as precipitation, temperature were taken from Meteo France Agency.

\subsection{Description of the variables}

\subsubsection{Price of water}

Data on rates and the length of consumption blocks were available from DIREN. The block rate schedule varies across municipalities (between 1 and 4 consumption blocks). As discussed by Taylor et al. (2004), the fixed charges are subtracted from the total bill to compute the average price to prevent bias in the estimated price elasticity. When the fixed portion of the bill is removed, the average variable price includes only the portion which varies with consumption.

\subsubsection{Household income}

The DIREN survey recorded household income level $^{1}$ as an ordered qualitative variable, namely as belonging to one of the following five income intervals (in Euros per month):

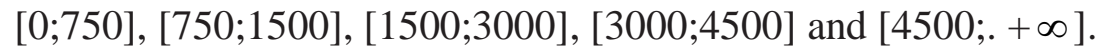

Unfortunately, this income information is not relevant to estimate the income elasticity of the water demand specification (9). Therefore, we used a quantitative estimate of the household income levels developed by Carlevaro et al. (2007). These estimates are based on an econometric model describing the observed qualitative information on household income according to an ordered polychotomous econometric model, where the unobserved household 
income level is specified as a latent variable. This unobserved variable is assumed to be distributed, within the household population, according to a log-normal random variable. Furthermore, the household income distribution is influenced by some household income indicators, recorded by the DIREN survey, to characterize the household standard of living. Finally, an individual income level estimate for each household of the DIREN sample is obtained by computing an estimate of the mean square error predictor of this latent variable, namely its expected value given all the available information at hand, including the income interval the household declared to belong to.

Note, that the household income level $Y$ of model (9) has been defined as the former household income level estimate adjusted by substracting the fixed charges of the water tariff schedule and adding the Nordin's difference variable (4), as explained in section 2.1.

\subsubsection{Climate variables}

The impact of climate on residential water use can be measured in different ways. In the literature, precipitation and temperature often are assumed to influence residential water demand. Schleich and Hillenbrand (2009) provided some evidence that households respond to whether it rains or not rather than to the total amount of rainfall. More precisely, we chose to use the percentage of non rainy days over the billing period, with the expectation that demand for garden water will be higher when the percentage of non rainy days is high.

We used daily observations recorded by Meteo France Agency (about one hundred stations set up on Réunion). These geographical distributed observations allowed us to compute the number of days without rainfall for each bill collected according to the observations recorded at the closest weather station. 


\subsubsection{Water-using capital stock and other variables collected}

We tested other explanatory variables, particular those measuring billing frequency, housing characteristics, consumption habits and the presence of a swimming-pool, dishwasher or washing machine. However, the parameters associated with all these variables turned out to be highly not significant ( $\mathrm{p}$-value greater than $30 \%$ ), probably due to the absence of information other than presence or absence. As variables such as appliance stocks are particularly useful in analyses of long term reactions to a price shock, which was not the focus of our study, we did not address this issue.

The set of available variables measured in 2004 and summary statistics for all variables are displayed in Table 1:

Table 1. Data set description, 449 water bills in 2004

\begin{tabular}{|lccc|}
\hline Description of variables & Mean & Min & Max \\
Daily water consumption per household & 675 & 102 & 5204 \\
(litres) & & & \\
Monthly household income (Euros) & 2096 & 426 & 7374 \\
Average price of water without fixed & 0.00089 & 0.000010 & 0.00218 \\
charges (Euros per litre) & 0.00118 & 0.00013 & \\
Marginal price of water (Euros per litre) & 0.91 & 0 & 3 \\
Household number of children & 0.98 & 0 & 5 \\
Household number of working adults & 1.29 & 0 & 100346 \\
Household number of non-working adults & 58 & 0 & 1.86 \\
Share of days without rainfall (\%) & 0.22 & 0.01 & 30.6 \\
Share of fixed charges in total income $(\%)$ & 2.8 & 0.19 & 5 \\
Share of water bill in total income (\%) & & & \\
\hline
\end{tabular}

In our sample, average residential water consumption is 675 litres per household per day 
(which correspond to 253 litres per capita on average). Coutelier and Le Jeannic (2007) confirm the pertinence of our estimates as they measured water consumption to be 269 litres per inhabitant on Réunion, which is similar to the highest consumption levels in the OECD. For example, the average daily per capita water use in the UE-15 countries ranges from 115 litres in Belgium to 265 litres in Spain, EWA (2002). On Réunion, per capita residential water consumption also is about $60 \%$ greater than in mainland France, on average. Water bills furthermore account for $2.8 \%$ of household income, on average, and up to $30 \%$ for the poorest consumers.

Distinctive features such as lifestyle (a high proportion of households live in a house with a garden) and climate may help explain these high water consumption levels. Water prices also are very low on Réunion (around one Euro per $\mathrm{m}^{3}$ in average). To conclude, the fixed charges represent a small part of household income, equal to $0.22 \%$ on average.

\section{Empirical estimation}

The estimation strategy is described in section 4.1, and empirical results are reported and discussed in section 4.2 .

\subsection{Estimation method}

One problem which must be addressed with multipart tariff pricing is simultaneity because consumers select the quantity of water and the price simultaneously. As an application of the the Breush-Pagan test also revealed the presence of heteroscedasticity, we chose to implement a GMM (Generalized Method of Moments) estimator, using an appropriate set of 
instruments $^{2}$, in order to deal with both econometric issues. Heteroskedasticity-robust standard errors estimates of parameter estimates were computed.

In the spirit of Hausman and Wise (1976), prices associated with fixed levels of consumption (the three first quartiles of the water consumption distribution) were used as instruments for marginal and average prices. Instrumental variables must satisfy two requirements. They must be correlated with the endogenous variable and be uncorrelated with the error term. We use the Bound et al. (1995) test to select relevant instruments and we perform the Hansen test of overidentifying restrictions to choose valid instruments.

\subsection{Results of model estimation}

The results of the GMM estimation of water demand model (9) are presented in Table 2:

Table 2. GMM estimation of water demand model (9)

\begin{tabular}{|cc|}
\hline Model parameters and tests & Parameter estimates ${ }^{a}$ and test statistics \\
$\alpha_{0}$ & 2.08 \\
Model intercept & $(1.11)$ \\
$\alpha_{1}$ & 0.29 \\
Income elasticity & $(0.82)$ \\
$\alpha_{2}$ & $-0.31^{* * *}$ \\
Perceived price elasticity & $(2.72)$ \\
$\alpha_{13}$ & $0.47^{* * *}$ \\
Household size elasticity & $(7.87)$ \\
$\alpha_{\prime^{*}}$ & 0.0044 \\
Rate of impact on household daily water & $(1.33)$ \\
\hline
\end{tabular}


consumption per percentage increase of non-

working adult share

$\begin{array}{ll}\alpha_{5} & 0.35^{*}\end{array}$

Rate of impact on household daily water

consumption for garden watering per

percentage increase of days without rainfall

$$
K
$$

Perception price parameter

t-test for $\mathrm{H}_{0}: k=1$

Hansen's overidentifying restrictions test:

OIR-statistic (p-value)

Adjusted R ${ }^{2}$

Number of observations

449

${ }^{a}$ Figures in brackets are t-statistics of parameter GMM estimators

Significance level for parameter estimates: *** for $1 \%$, ** for $5 \%$ and * for $10 \%$

Hansen's test statistic, which is asymptotically distributed as a $\chi^{2}(1)$ indicates that the population moment conditions are not rejected, implying the validity of the choosen instruments. The adjusted $\mathrm{R}^{2}$ is quite low but this is typical with microeconomic survey data.

The parameter estimates deserve the following comments.

- The income elasticity has the expected positive sign but is not statistically significant, probably due to the errors inherent in the indirect method of measurement used for quantifying this explanatory variable. Its low numerical value, equal to 0.29 , reflects 
the feature of basic need of water consumption for the majority of households.

- The estimate of the perceived price elasticity obtained is equal to -0.31 and is statistically different from zero. This value is in the range of the estimates found in the applied econometric literature and expresses the difficulty of substituting water with other goods, except through an household saving behavior.

- We observe a positive and highly significant impact of household size on its water consumption. According to our estimate, an increase of $10 \%$ in the family size will result in an increase of $4.7 \%$ in its daily consumption of water. This result can be understood by the existence of household economies of scale in the use of water (Garcia-Valiñas 2005).

- As expected, a working adult consume less water at home than a non-working adult. Hower, the impact of an increase of 10 percentage points in the share of non-working adults with respect to the total number of adults in the household increases the household consumption of water by only $0.044 \%$ and this impact is not statistically significant.

- As expected, the presence of a garden, combined with a low occurrence of rainfall, has a positive impact upon water consumption. More precisely, a 10\% increase of the days without rainfall increases the household water consumption of $3.5 \%$, but this impact is weakly significant.

- The perception price parameter estimate is equal to 1.53 , reflecting a perceived price not only less than the marginal price but also less than the average price. This indicates that Réunion households highly underestimate the price of water. From a statistical point of view, the price perception parameter is significantly different from zero (the value for which perceived price is equal to marginal price), but not significantly different from 1 (the value for which perceived price is equal to average 
price). This result contrast with Nieswiadomy and Molina (1991), as they concluded that under increasing block rates, water consumers react to marginal price. But their analysis is based on a monthly time series between 1976 and 1985 of aggregate water consumption of the city of Denton, Texas, U.S.A. Therefore, their conclusion could be the result of an aggregation bias. Our explanation is that households of Réunion receive billing information, on the amount of water bill and of water consumption, enabling them to assess only a rough average price perception.

As a consequence, increasing the billing information of Réunion households on the actual marginal price of water they pay may noticeably reduce their consumption of water and therefore contribute to a sustainable use of this scare resource of the island. To our knowledge, Gaudin (2006) has been the first to analyze the effects of billing price information on residential water demand. Her study shows that billing price information increases the value of water price elasticity.

To gain a better insight on the effectiveness of such an information policy on residential water saving, we simulate the impact of the presence of marginal price information on the bill on water consumption. We compare simulated water consumption levels obtained through estimated equation (9), by assuming that consumers respond to a perceived price defined by formula (6) with a perception price parameter $k=1.53$, to consumption levels obtained by assuming that consumers respond to marginal price $(\mathrm{k}=0)$. Using an average price as defined in section 3.2.1 (by excluding fixed charges), our simulations show that the household sample average water consumption level would decrease from 432 to 362 litres per household per day. These simulated results correspond to a drop in residential water consumption of $16 \%$. We conclude that the use of clear marginal price information as a water conservation policy 
could be advocated, in order to significantly reduce residential water consumption on Réunion.

\section{Conclusions}

This article examines the household's perception of the price of water under an increasing block rate schedule by assuming that residential water consumers are not well-informed about the marginal price at which a rational consumer should respond. To estimate an unbiased value for the price elasticity of water, we use a methodology developed by Shin (1985). This methodology is based on a specification of the water price perception as a weighted geometric average of marginal and average prices, where the weight plays the role of a price perception parameter leading to one of these two prices depending on whether its value is 0 or 1 . Thus, the relevant price perception specification can be identified by estimating and testing the value of the price perception parameter within an econometric specification of residential water demand.

Using a unique sample of water bills collected from a household survey on the French overseas territory of Réunion, our main finding suggests that the perceived price to which consumers respond is not only less than the marginal price but also less than the average price. This indicates that Réunion households highly underestimate the price of water. Therefore, the addition of marginal price information on the bill alongside the quantity consumed could be an effective simple device to help reduce water consumption.

Using our model estimate, we assess by simulation the magnitude of the impact of such an information pricing policy on water conservation. Our simulation shows that if the survey households set their water demand according to marginal price instead of perceived price, then their average water consumption would decline substantially (from 432 to 362 litres per 
household per day, on average). As the block rates schedules remain the same, the distributional effects of such a clearer price policy are negligible compared to those resulting from a traditional pricing policy. The welfare and distribution effects of changes in block price systems are evaluated by Ruijs (2009) for example. We conclude that the use of clearer information on marginal prices should be considered in conservation policy as it should lead to lower water bills for all the consumers who reduce water consumption. Furthermore, it does not compromise the financial situation of the water companies as block rates are unchanged.

From a policy perspective, this price information policy could be extended, as recommended by Thaler and Sunstein (2008), to give consumers incentives to adopt ('to nudge') by themselves water conservation behaviours. The general idea is that water can be saved simply by suggesting the right options to households without imposing constraints. For example, the Southern California Edison company succeeded in reducing household electricity consumption by $40 \%$ by providing an 'ambient orb' which turns red when consumption is excessive and green when moderate. Another application of such a policy also involves electricity consumption. In California, electricity bills include information about small water users' average consumption to encourage electricity saving by mimicking these consumption targets. To conclude, future analyses based on behavioral economics could provide more insights into the sensibility of water users to billing information and effective changes in water consumption behavior.

\section{Notes}

1. Households were asked to include all their income sources, including wages, welfare 
benefits, property revenues, ...

2. Once the endogeneity in the price variable had been purged via IV or GMM estimators, the price coefficient estimate acquired the expected sign, whereas it was positive with the simple OLS technique.

\section{References}

Arbuès F, Garcia-Valinas M A, Martinez-Espineira R (2003) Estimation of residential water demand: a state-of-the-art review. J Socio-Econ 32 (1): 81-102

Bound J, Jaeger D A, Baker R M (1995) Problems with instrumental variables estimation when the correlation between the instruments and the endogeneous explanatory variable is weak. J Am Statistical Association 90: 443-50

Carlevaro F, Schlesser C, Binet M E, Durand S, Paul M (2007) Econometric modeling and analysis of residential water demand based on unbalanced data. Appl Econometrics 4 (8) : 81100

Coutelier A, Le Jeannic F (2007) La facture d'eau domestique en 2004, 177 Euros par personne et par an. Le 4 pages ifen (Institut Français de 1'Environnement) $117: 1$-4

Dalhuisen J M, Florax R J G, De Groot H L F, Nijkamp P (2003) Price and income elasticities of residential water demand: a meta analysis. Land Econ 79 (2): 292-308

EWA (2002), European Water Association, European Water Association Yearbook.

Foster H S, Beattie B R (1981) On the specification of price in studies of consumer demand under block price scheduling. Land Econ 57(4): 624-29

Gaudin S (2006) Effect of price information on residential water demand. Appl Econ 38(4): 
Garcia-Valiñas M A (2005) Efficiency and equity in natural resources pricing: A proposal for urban water distribution service. Environ Resour Econ 32(2): 183-204

Hausman J A, Wise D A (1976) The evaluation of results from truncated samples: The New Jersey income maintenance experiment Annals Econ Social Measurement 5(4): 421-45

Howe C W, Linaweaver F P (1967) The impact of price on residential water demand and its relation to system design and price structure. Water Resour Research 3(1): 13-32

Kavezeri-Karuaihe S T, Wandschneider P, Yoder J (2005) Perceived water prices and estimated water demand in the residential sector of Windhoek, Namibia: an analysis of different water market segments. Working Paper number 36289, San Francisco, California

Nauges C, Whittington D (2010) Estimation of water demand in developing countries: An overview. World Bank Research Observer 25(2): 263-294

Nieswiadomy M L, Molina D J (1991) A note of price perception in water demand models. Land Econ 67(3): 352-59

Nieswiadomy M L (1992) Estimating urban residential water demand: effects of price structure, conservation, and education. Water Resour Research 28(3): 609-15

Nieswiadomy M L, Cobb S L (1993) Impact of pricing structure selectivity on urban water demand. Comtemporary Policy Issue 11(3): 101-13

Nordin J A (1976) A proposed modification on Taylor's demand analysis: Comment. Bell J Econ 7(2): 719-721

Opaluch J (1982) Urban residential demand for water in the United States: further discussion. Land Econ 58 (2): 225-27

Ruijs A, Zimmerman A, Van Den Berg M (2008) Demand and distributional effects of water 
pricing policies Ecol Econ 66(2-3): 506-16

Ruijs A (2009) Welfare and distribution effects of water pricing policies. Environ Resour Econ 43(2): 161-82

Schleich J, Hillenbrand T (2009) Determinants of residential water demand in Germany. Ecol Econ 68(6): 1756-69

Shin J S (1985) Perception of price when price information is costly: Evidence from residential electricity demand. Rev Econ Statistics 67(4): 591-98

Taylor R G, McKean J R, Young R A (2004) Alternative price specifications for estimating residential water demand with fixed fees. Land Econ 80(3): 463-475

Thaler R H, Sunstein C R (2008) Nudge: improving decisions about health, wealth, and happiness, New Haven and London, Yale University Press.

Worthington A C, Hoffman M (2008) An empirical survey of residential water demand modelling. J Eco Surveys 22(5): 842-71 